\title{
Effects of Short-form Advertising Influencer Properties on Advertising Information, Advertising Entertainment, and Personalization Characteristics of Advertisement
}

\section{솟폼광고 인플루언서의 속성이 광고 정보성, 광고 오락성, 광고의 개인화 특성에 미치는 영향}

Eun Hee $\operatorname{Kim}^{1}$

김은희 ${ }^{1}$

${ }^{1}$ Assistant Professor, Division of Advertising \& PR Communications, Mokwon University, Korea, eunhee0103@mokwon.ac.kr

\begin{abstract}
As short-form content is growing rapidly and is attracting attention in the advertising market along with influencers. Therefore, in this study, the attributes of influencers in advertisements using short-form contents were confirmed, and how influencers attributes affect advertisement information, entertainment, and personalization characteristics of advertisements. Variables for research analysis were influencer characteristics, advertisement information, entertainment, and personalization characteristics of advertisements, all of which used a Likert-type 5-point scale frequency analysis, factor analysis, and multiple regression analysis were used to confirm demographic characteristics. As a result of the study, the attributes of influencers in short form advertisements were identified as five factors: professionalism, dynamics, reliability, propagation, and intimacy. Among the attributes of influencers, the factors that influence advertising information and entertainment were identified as propagation, dynamism, and reliability. It was confirmed that the propagation of the influencer's attributes had an influence on the personalization characteristics of short-form advertisements. This study is intended to confirm the influence of the influencer's attribute in the short-form advertisement on the short-form advertisement and suggest practical implications that are useful for the influencer strategy of the shortform advertisement.
\end{abstract}

Keywords: Short-form Advertisement, Influencer, Advertisement Information, Advertisement Entertainment, Personalization Characteristics of Advertisement

요약: 숏폼 콘텐츠가 급성장하면서 인플루언서와 함께 광고시장에서 주목받고 있다. 이에 본 연구에서는 솟폼 콘텐츠를 활용한 광고 속 인플루언서의 속성을 확인하고, 인플루언서 속성이 광고 정보성과 오락성 그리고 광고의 개인화 특성에는 어떠한 영향을 미치는지 확인하였다. 연구의 응답자는 숏폼 콘텐츠 사용이 가장 많은 $\mathrm{Z}$ 세대를 대상으로 이루어졌다. 연구 분석을 위한 변인은 인플루언서 특성, 광고 정보성, 오락성, 광고의 개인화 특성으로 구성하였다. 이들 변인은 모두 리커트형 5점 척도를 활용하였다. 분석 방법은 인구통계학적 특성을 확인하기 위한 빈도 분석과 요인분석, 다중회귀분석을 활용하였다. 연구 결과, 숏폼광고 속 인플루언서의 속성은 전문성, 역동성, 신뢰성, 전파성, 친밀성 5 개 요인으로 도출되었다.

Received: March 08, 2021; $1^{\text {st }}$ Review Result: April 24, 2021; $2^{\text {nd }}$ Review Result: June 11, 2021 Accepted: July 31, 2021 
인플루언서의 속성 중 광고 정보성과 오락성에 영향을 미치는 요인은 전파성, 역동성, 신뢰성으로 확인되었다. 솟폼광고의 개인화 특성에는 인플루언서의 속성 중 전파성이 영향을 미치는 것으로 확인되었다. 이상의 연구는 숏폼 광고 속 인플루언서의 속성이 숏폼광고에 미치는 영향력을 검증하였다는 학문적 의의와 솟폼광고의 인플루언서 전략에 유용한 실무적 시사점을 제안한 것에 의의가 있다.

핵심어: 숏폼광고, 인플루언서, 광고 정보성, 광고 오락성, 광고의 개인화 특성

\section{1. 서론}

미디어 패러다임의 변화는 모바일을 토대로 디지털 콘텐츠 시장을 활성화 시켰다. 이러한 변화는 광고산업에도 지대한 영향을 미쳤다. 20년간 절대적 위상을 유지해 온 방송 매체가 2016년을 기점으로 모바일 중심의 소셜미디어로 광고시장이 이동한 것이다. 디지털 기술을 활용한 소셜 미디어 서비스는 모바일 시장이 성숙기에 이르면서 미디어 이용자들의 콘텐츠 소비행태도 변화시켰다. 필요한 정보를 직접 검색해서 사용하던 적극적인 소비에서 이제는 페이스북이나 유튜브 등 소셜미디어에 노출된 콘텐츠를 선택하여 소비하는 소극적 패턴으로 변화하고 있다[1]. 이는 디지털 콘텐츠를 활용한 마케팅 커뮤니케이션에 새로운 생태계가 형성되었음을 의미한다.

디지털 콘텐츠는 이제 기업의 주요 마케팅 도구로 활용되고 있다. 소셜 미디어를 기반으로 디지털 콘텐츠 마케팅, 인플루언서 마케팅 그리고 솟폼 콘텐츠로 성장하고 있다. 최근 주목받고 있는 숏폼 콘텐츠는 숏폼 형태의 짧고 간결한 영상 콘텐츠를 의미한다[2]. 기존의 플랫폼보다는 모바일을 기반으로 활용하기에 적합한 짧은 영상으로 몇 초 이내에서 10 분 내외로 구성되어 있다[3].

숏폼 콘텐츠의 주 이용층은 디지털 네이티브 $\mathrm{Z}$ 세대이다. 이들의 콘텐츠 소비행태에 맞춰 더 간편하고 간결하며 더 강렬하게 15 초 동안 매력을 어필하며[4], 새로운 문화 트렌드로 부상하고 있다. 솟폼 콘텐츠가 $\mathrm{Z}$ 세대를 중심으로 확산되고 선호도가 높아짐에 따라 기업의 디지털 기반 광고구조 역시 솟폼 콘텐츠와 유사한 양상으로 변화하고 있다[5].

광고 커뮤니케이션 도구로써 자리매김하고 있는 숏폼 콘텐츠는 틱톡을 중심으로 $\mathrm{Z}$ 세대에게 스낵컬쳐로 각광을 받고 있다. 이러한 맥락에서 기업은 1 인미디어를 기반으로 콘텐츠를 생산하고 공유하는 인플루언서의 영향력을 활용하여 숏폼 광고를 자연스럽게 노출하고 있다. 인플루언서는 디지털 미디어 플랫폼에서 타인에게 영향력을 미치는 사람이다[6]. 인플루언서의 매력성과 신뢰성은 소비자들에게 정보의 유용성과 지각된 즐거움에 호의적인 영향을 미친다[7]. 그러므로 기업은 잠재고객과의 긍정적 관계를 형성하기 위해 인플루언서 마케팅을 적극적으로 활용하고 있다.

숏폼 콘텐츠의 광고효과는 2019년 메조미디어 리서치 결과에서 잘 알 수 있다. 브랜드 인지도 $(87.5 \%)$ 와 제품을 이해하는 정보수용 $(73.7 \%)$ 측면에서 동영상 광고의 길이가 15 초 이하일 때 광고효과가 더 높다는 것이다. 이처럼 광고효과가 높은 Z세대를 중심으로 성공 사례가 증가하면서 최근 주요 소셜 미디어들은 숏폼광고를 확대하며 광고제작을 강화하는 계획을 제시하고 있다[5].

이상의 논점을 정리하면 숏폼 콘텐츠의 성공은 숏폼광고 확산에도 영향이 미치고 있음을 알 수 있다. 또한 소셜 미디어 플랫폼에 등장하는 정보원 즉, 인플루언서 
마케팅을 활용하여 숏폼광고 확산과 발전 가능성을 살펴볼 수 있다. 그러나 이러한 실무적 현실과는 달리 숏폼광고의 학계 연구는 전무한 상황이라고 볼 수 있기에 광고정보원으로 등장하는 인플루언서의 영향력과 숏폼광고 효과를 확인할 필요성이 제기된다.

따라서 본 연구의 목적은 다음과 같다. 첫째, 솟폼광고 특성으로 인한 광고효과는 어떠한지 확인하고자 광고 정보원으로 등장하고 있는 인플루언서의 속성을 먼저 살펴보고자 한다. 인플루언서의 속성은 소셜 미디어를 중심으로 다수의 연구가 진행되었다. 그러나 본 연구는 기존의 디지털 콘텐츠와는 차별적 특성이 있는 솟폼광고 속에 등장하는 소셜 인플루언서의 속성을 확인하고자 한다. 둘째, 펀(Fun)과 패스트(Fast) 콘텐츠를 즐기는 $\mathrm{Z}$ 세대들은 소셜 인플루언서의 속성 중 어떠한 요인들이 솟폼광고의 정보성, 오락성, 그리고 광고 개인화 특성에 영향을 미치는 그리고 그 영향력은 어떠한지 확인하고자 한다. 이상의 연구는 솟폼광고 속 인플루언서의 속성을 밝히는 학문적 의의와 소셜 인플루언서 속성이 숏폼광고에 어떠한 영향을 미치는지 실무적 시사점을 제공하고자 한다.

\section{2. 이론적 배경 및 선행연구}

\section{1 숏폼 콘텐츠와 광고}

콘텐츠 마케팅은 디지털 네이티브라고 불리는 $\mathrm{Z}$ 세대를 중심으로 막대한 영향력 발휘하여 이들의 소비행태에 맞춰 콘텐츠 패턴에 변화가 일어나고 있다. 더 간편하며 간결한 형태의 숏폼 콘텐츠 소비가 증가하고 있다. 솟폼 콘텐츠는 짧은 길이의 영상 콘텐츠를 의미한다[2]. 스낵컬처로 이용자들이 부담 없이 간편하게 즐길 수 있는 스낵컬쳐[8]로 짧게는 15 초, 길게는 10 분 길이의 영상 콘텐츠이다[3]. 틱톡을 필두로 유튜브, 인스타그램, 페이스북, 넷플릭스, 애플+ 등 다양한 미디어로 솟폼 콘텐츠 서비스가 확산되고 있다[3]. 글로벌 IT 플랫폼 기업들의 영상콘텐츠 제작 툴 서비스를 제공함으로써 이용자 누구나 쉽게 촬영하고 편집하며 참여하고 공유, 확산되고 있다.

숏폼 콘텐츠의 성장 배경을 살펴보면 다음과 같이 정리할 수 있다. 첫째, 미디어 사용 중 영상 콘텐츠의 비중 증가 둘째, 코로나 19 로 인한 언택스 시대에 영상과 앱 사용률 증가 셋째, 이용의 편리성에 따른 동영상 소비패턴의 변화 넷째, 롱폼이 아닌 숏폼으로 영상 플랫폼 사용 패턴의 변화 다섯째, 이미지에서 영상 중심의 소통 대세[9] 여섯째, 세로영상의 대중화 일곱번째, 누구나 쉽게 크리에이터가 가능하다[10]는 것이다.

재미를 생산하고 소비하는 솟폼 콘텐츠의 성공에도 불구하고 학계의 솟폼 콘텐츠 연구는 초기 단계에 머물러 있다. 숏폼 콘텐츠 연구는 시작 단계로 숏폼 콘텐츠의 이용동기[8]를 중심으로 수용인식[11]과 유형[12] 그리고 광고 콘텐츠로서의 가능성을 살펴보는 연구[13] 만이 진행되고 있다. 먼저, 짧은 동영상이라는 개념으로 솟폼 콘텐츠의 이용동기는 습관적 소비, 접근성, 간결성, 상호작용, 질적 우수, 반복성, 조작의 편리성이라고 이유진, 유세경[8]은 설명하였다. 이들의 연구에서 살펴볼 수 있는 것은 전문 제작자가 제공하는 콘텐츠는 습관적 소비, 상호작용성, 반복성이 영향을 미치지만 일반인들이 제작한 숏폼 콘텐츠는 습관적 소비, 상호작용성과 간결성으로 이용동기의 차이점이 발견된다.

숏폼 콘텐츠의 선두주자인 틱톡에 대한 수용자의 인식을 살펴본 이문학과 정현욱[11]은 틱톡 인식을 3 개의 유형으로 정리하였다. 첫째, 정보나 지식을 확보하기 위한 궁금증 
해소 둘째, 스트레스 해소와 재미를 추구하기 위한 긴장감 해소 셋째, 휴식과 여가활용을 위해 무료함 해소의 3 가지 유형이다. 또한 유형 간의 공통점을 정보 및 지식을 확보하기 위함이지만 중독에 관한 부정적 인식도 살펴볼 수 있었음을 제시하였다.

틱톡 광고와 기존 광고와의 차이점을 살펴본 마뤼야오와 김소정[13]은 틱톡광고는 건너뛰기 조작이 간단해서 다른 앱보다 편리함을 가지고 있으며 유명인을 광고 모델로 섭외하지 않아 친근감을 느낄 수 있다고 설명하였다. 그러므로 이용자들은 틱톡 광고를 싫어하기보다 광고주가 제공한 스티커나 음악을 활용하여 광고에 적극 참여한다고 밝혔다.

이상의 연구들을 정리하면 짧은 영상에서 시작된 솟폼 콘텐츠는 $\mathrm{Z}$ 세대를 중심으로 관심있는 정보와 지식을 확보하기 목적지향과 감정욕구를 충족하기 위한 통로 등으로 인식되고 있음을 알 수 있다. 숏폼 콘텐츠에서 제공하는 광고는 기존 광고와는 달리 거부감이 적고 높은 상호작용성과 재미로 인해 이용자들의 적극인 참여를 이끌어내고 있다. 따라서 본 연구에서는 선행연구를 토대로 숏폼 광고의 특성을 고려하여 광고의 정보성과 오락성 그리고 이용자 개인에게 제공하는 광고의 적합성을 결과변인으로 설정하여 본 연구의 목적을 탐구하고자 한다.

\section{2 인플루언서}

인플루언서는 ‘영향력을 행사하는 사람’을 의미한다[14]. 소셜 미디어 등의 1 인 미디어 플랫폼을 활용하여 콘텐츠를 직접 제작하고 유통하며 자신의 메시지를 전달하는 영향력을 가진 이[6]를 일컫는 신조어이다. 인플루언서의 온라인 개인방송은 라이브 방송 콘텐츠 시청 경험을 공유하고 방송과 쌍방향 커뮤니케이션이라는 가치를 제공한다[15]. 또한 인플루언서는 소셜 미디어 플랫폼을 통해 이용자들과 상호작용이 탁월하기에 기업은 이들의 파급효과를 제품이나 서비스를 홍보하기 위한 마케팅전략으로 활용하고 있다. 디지털 마케팅의 성장세와 더불어 이를 인플루언서 마케팅이라고 한다[14].

인플루언서 마케팅이 마케팅과 광고 및 홍보 분야에서 관심을 받는 이유는 세 가지로 설명할 수 있다. 첫째, 유명 연예인이 등장하는 광고와는 달리 소셜 미디어 인플루언서가 등장하는 광고는 정보원에 대한 높은 친밀성과 신뢰성, 관련성을 느낄 수 있어 메시지의 높은 설득력이다[16][17]. 둘째, 전통적인 광고보다 상업적 특성이나 부정적 태도 유발 가능성이 낮아 거부감없는 접근성이다[17]. 셋째, 메시지 도달범위와 도달빈도 및 설득 측면에서 타깃팅 효과의 극대화가 가능하다는 것이다.

인플루언서의 커뮤니케이션 역량과 효과성은 제품 서비스와 유통 그리고 미디어 산업 등 전반에 걸쳐 마케팅 트렌드로 성장하고 있음을 알 수 있다[18]. 이러한 맥락에서 학계에서도 인플루언서를 활용한 효과성[7][16][17]과 부정적 태도[7][15][19]등의 연구들이 진행되고 있다.

유튜브 플랫폼을 중심으로 인플루언서 정보원 속성을 확인하기 위해 김혜영과 최준혁[15]은 4 개의 구성요인과 19 개의 문항을 개발하였다. 인플루언서 정보원의 구성 요소는 탁월성, 콘텐츠 적합성, 적극성, 유사성의 4 개 척도를 중심으로 19 개의 문항으로 구성되어 있다. 이들의 연구는 인플루언서의 커뮤니케이션 활동과 이들의 활용성을 판단할 수 있는 기준으로 활용될 수 있을 것이다. 박소진과 오창규[7]는 인플루언서의 속성이 유튜브 정보수용과 구매의도에 미치는 영향을 살펴보고자 정보원천으로서의 전통적 광고모델을 토대로 연구가 이루어졌다. 이들은 유튜버의 신뢰성을 전문성과 
진실성, 유튜버의 매력을 호감성, 유사성, 친숙성으로 제시하며 지각된 정보의 유용성과 즐거움 그리고 구매의도를 살펴보았다[7].

이상의 선행연구에서 제시된 바와 같이 다수의 연구들은 인플루언서의 속성을 전통적 광고모델 연구를 토대로 진행되었음을 알 수 있다. 그러나 인플루언서는 크게 연예인을 기반으로 한 인플루언서와 소셜 미디어 플랫폼을 토대로 성장한 인플루언서로 구분할 수 있다[19]. 연예인 인플루언서는 전통적 미디어를 통해 대중들에게 알려진 유명인이라면 소셜 미디어 인플루언서는 소셜 미디어 내에서 다수의 추종자을 보유한 영향력 있는 의견선도자[19]이며 정보원이다. 그러므로 대중매체를 통해 성장한 연예인 인플루언서와 소셜 미디어 플랫폼을 기반으로 성장한 인플루언서와는 구별된다. 따라서 본 연구에서는 소셜 미디어 플랫폼에서 성장하여 솟폼 콘텐츠 정보원으로 활동하고 있는 소셜 인플루언서들의 속성을 살펴보고 이들의 속성이 숏폼광고에 미치는 영향력을 확인하고자 한다.

\section{3 연구문제}

광고와 콘텐츠의 경계가 모호해진 현 시점에 기업은 그들의 정보를 제공하기 위하여 소셜 미디어를 활용한 디지털 콘텐츠 마케팅에 심혈을 기울이고 있다. 이러한 맥락에서 기업은 미래 고객인 $\mathrm{Z}$ 세대를 중심으로 성장하고 있는 솟폼 콘텐츠에 관심을 가지며 인플 루언서를 활용한 숏폼 콘텐츠를 광고 커뮤니케이션 도구로 활용하고 있다. 이에 본 연구 에서는 기업의 새로운 광고 정보원으로 등장하고 있는 소셜 인플루언서가 숏폼광고에서 어떠한 속성을 갖고 있는지 확인하고자 하였다. 또한 인플루언서의 속성 중 숏폼광고의 정보성과 광고 오락성 그리고 솟폼 콘텐츠가 가지고 있는 특성 중 광고의 개인화에 영향 을 미치는 요인이 무엇이며 그 영향력을 확인하고자 하였다. 이를 확인하기 위한 연구문 제는 다음과 같다.

연구문제 1. 숏폼 광고 속 인플루언서 특성은 어떠한 요인으로 구성되어 있는가?

연구문제 2. 숏폼 광고 속 인플루언서 특성 요인 중 어떠한 요인이 광고 정보성에 영향을 미치는가?

연구문제 3. 숏폼 광고 속 인플루언서 특성 요인 중 어떠한 요인이 광고 오락성에 영향을 미치는가?

연구문제 4. 솟폼 광고 속 인플루언서 특성 요인 중 어떠한 요인이 광고의 개인화 특성에 영향을 미치는가?

\section{3. 연구 방법}

\section{1 사전 조사}

숏폼광고 속에 등장하는 인플루언서의 속성을 확인하기 위하여 선행연구에서 정리된 항목을 토대로 광고 전공 대학원생 2 명과 광고 전문가 2 명을 대상으로 사전 조사가 이루 어졌다. 사전 조사는 이들에게 솟폼광고 7편을 보여주고 광고 속 등장인물 인플루언서가 어떠한 속성이 있는지 반구조화된 질문지를 토대로 인터뷰를 진행하였다. 인터뷰는 숏폼 광고에 등장하는 인플루언서의 특성이나 속성을 자유롭게 제시해 주도록 요청하였다. 사 전 조사와 선행연구를 토대로 숏폼광고 속에 등장하는 소셜 인플루언서의 특성은 설명력 이 뛰어나다, 광고에 적합한 인물이다, 전문가 같다, 호감이 간다, 경험이 풍부하다, 편안 
하다, 친근하다, 재미있다, 지인에게 추천하고 싶다, 매력적이다 라는 결과를 도출하였다. 인플루언서의 특성은 사전 조사에서 도출한 항목과 선행연구에서 도출한 항목을 재정리 하였다. 그 결과 본 연구는 숏폼광고에 등장한 인플루언서의 속성을 전문성, 역동성, 신 뢰성, 전파성, 친밀성으로 구성된 측정 항목을 설정하였다.

\section{2 본조사}

\subsection{1 응답자}

솟폼콘텐츠를 가장 많이 소비하는 $\mathrm{Z}$ 세대이다. 이들을 디지털 네이티브 세대라고도 한 다. 따라서 Z세대를 대표하는 대학생들을 본 연구의 응답자로 선정하였다. 설문은 숏폼광 고를 본적이 있다고 응답한 이들을 대상으로 조사가 이루어졌다. 설문조사는 2020년 11월 23 일부터 12월 4일까지 실시하였다. 설문조사에 참여한 대학생은 147 명이며 남학생 56명 (38.1\%), 여학생은 91명(61.9\%)이다. 조사에 참여한 응답자들의 평균 연령은 22.9 세이다. 이들의 하루 소셜 미디어 이용 시간은 평균 235 분으로 확인되었다.

\subsection{2 척도와 조작적 정의}

\subsubsection{1 소셜 인플루언서 속성}

본 연구에서 소셜 인플루어서의 속성은 메시지를 전달하는 정보원으로서의 전문성과 신뢰성 그리고 친근함과 생기발랄함을 갖춘 영향력을 조작적 정의로 정리하였다. 이를 측정하고자 전문성은 지식과 경험이 풍부하다는 의미로 정의하였다. 측정항목은 사전 조 사와 김종무[20]의 연구에서 사용한 척도를 활용하였다. 역동성은 메시지를 전달하는 정 보원이 생기있고 활기차게 보이는 것이다. 이를 측정하기 위해 사전 조사와 박성애[21] 의 연구에서 사용한 척도를 활용하였다. 신뢰성은 믿을만하고 진실하다는 의미로 정의하 였다. 이를 측정하고자 사전 조사와 조재현[22] 연구에서 사용한 척도를 활용하였다. 전파 능력은 영상이나 게시물을 공유하고 따라하고 싶은 영향력으로 정의하였다. 이를 측정하 고자 사전 조사와 박성애[21] 의 연구에서 사용한 척도를 활용하였다. 친밀성은 소비자가 정보수용과정에서 편안함이나 친근함을 느끼는 것이다. 이를 측정하고자 사전 조사와 권 유진 등[23] 의 연구에서 사용한 척도를 활용하였다. 소셜 인플루언서 특징을 구성하고 있는 17 개 항목의 내적일치도를 확인한 결과 Cronbach's $\alpha$ 값은 .937로 확인되었다.

\subsubsection{2 광고 정보성}

광고 정보성은 솟폼 광고 콘텐츠에서 제공한 유익한 정보를 의미한다. 이를 확인하기 위하여 김승권과 윤종수[24]의 연구에서 사용한 척도를 본 연구에 맞게 재정리하여 사용 하였다. 측정 문항은 숏폼 광고는 나에게 상품정보를 제공한다, 솟폼 광고는 나에게 최신 정보를 제공한다, 솟폼 광고는 나에게 유익한 정보를 제공한다, 솟폼 광고는 나에게 필요 한 정보를 제공한다의 4 개 문항이다. 이들 문항들의 내적일치도를 확인한 결과 Cronbach's $\alpha$ 값이 .871 로 확인되었다.

\subsubsection{3 광고 오락성}

광고 오락성은 숏폼 광고 콘텐츠에서 제공하는 즐거움과 유쾌함을 의미한다. 이를 측정하기 위하여 김승권과 윤종수[24]가 사용한 척도를 본 연구에 맞게 재정리하여 사용하였다. 측정문항은 숏폼 광고는 유쾌하다, 숏폼 광고는 나에게 즐거움을 준다, 숏폼 
광고를 보면 나는 기분이 좋아진다, 숏폼 광고는 흥미롭다의 4 개 문항이다. 이들 문항들의 내적일치도를 확인한 결과 Cronbach's $\alpha$ 값이 .809 확인되었다.

\subsubsection{4 광고의 개인화 특성}

광고의 개인화 특성은 광고 콘텐츠가 이용자 개인에게 적합하거나 관심있는 제품정보 제공하였느냐를 의미한다. 이를 확인하고자 Bauer et al[25]의 연구에서 사용한 척도를 본 연구에 맞게 재정리하여 사용하였다. 측정문항은 솟폼 광고는 나의 욕구에 부응하는 제품정보를 제공한다, 숏폼 광고는 나에게 적합한 제품정보를 제공한다, 숏폼 광고는 내가 관심 있는 제품정보를 제공한다, 솟폼 광고의 콘텐츠는 개인에게 최적화되어 있다의 4 개 문항이다. 이들 문항의 내적일치도는 Cronbach's $\alpha$ 값이 .854 로 확인되었다.

\section{4. 분석결과}

\section{1 연구문제 1}

인플루언서 속성을 구성하고 있는 항목들의 타당성을 검증하고자 탐색적 요인분석을 실시하였다. 분석결과는 [Table 1]과 같다. 먼저 Kaiser-Meyer-Olkin와 Bartlett의 구형성 검정을 활용하여 요인분석의 적합성을 확인하였다. 그 결과 $\mathrm{KMO}$ 값은 .860이며, Bartlett 검증 카이제곱은 $1874.123(\mathrm{df}=120, \mathrm{Sig}=.000)$ 으로 확인되었다. 따라서 요인분석에는 문제가 없는 것으로 판단하였다. 일반적으로 요인분석에서 공통성과 요인적재량이 .4 이하이면 낮다고 판단한다. 그러나 본 연구에서 공통성과 요인적재량 모두 .7이상으로 확인되었다. 전체 분산 설명력은 $82.479 \%$ 로 확인되었다. 인플루언서 속성을 구성하고 있는 17 개의 항목 중 요인으로 묶이지 않는 1 개의 항목을 제외한 결과 5 개의 요인으로 도출되었다. 제 1 요인은 4 개의 문항으로 이루어졌으며 요인명은 전문성으로 명명하였다. 이들 항목의 내적 일치도를 확인한 결과 Cronbach's $\alpha$ 값은 .873으로 확인되었다. 제 2 요인은 3 개의 문항으로 이루어졌으며 요인명은 역동성으로 명명하였다. 이들 항목의 내적 일치도를 확인한 결과 Cronbach's $\alpha$ 값은 .836으로 확인되었다. 제 3 요인은 3 개의 문항으로 이루어졌으며 요인명은 신뢰성으로 명명하였다. 이들 항목의 내적 일치도를 확인한 결과 Cronbach's $\alpha$ 값은 .914으로 확인되었다. 제 4요인은 3 개의 문항으로 구성되었으며 요인명은 전파성으로 명명하였다. 이들 항목의 내적 일치도를 확인한 결과 Cronbach's $\alpha$ 값은 .894으로 확인되었다. 제 5요인은 3개의 문항으로 이루어졌으며 요인명은 친밀성으로 명명하였다. 이들 항목의 내적 일치도를 확인한 결과 Cronbach's $\alpha$ 값은 .930으로 확인되었다. 이상의 결과를 정리하면 솟폼 광고 속에 등장하는 인플루언서 속성은 전문성, 역동성, 신뢰성, 전파성, 친밀성의 5 개 요인이 도출되었음을 확인하였다.

[표 1] 인플루언서 속성 요인분석

[Table 1] Influencer Attribute Factor Analysis

\begin{tabular}{|c|c|c|c|c|c|c|}
\hline \multirow{2}{*}{ 항목 } & \multicolumn{7}{|c|}{ 요인 } \\
\cline { 2 - 7 } & 요인 1 & 요인 2 & 요인 3 & 요인 4 & 요인 5 & 공통성 \\
\hline 이 분야에 적합하다 & .809 & & & & & .781 \\
\hline 전문성이 있다 & .757 & & & & & .771 \\
\hline
\end{tabular}


Effects of Short-form Advertising Influencer Properties on Advertising Information, Advertising Entertainment, and Personalization Characteristics of Advertisement

\begin{tabular}{|c|c|c|c|c|c|c|}
\hline 지식이 풍부하다 & .738 & & & & & .730 \\
\hline 이 분야에 경험이 풍부하다 & .737 & & & & & .728 \\
\hline 생기 발랄하다 & & .932 & & & & .903 \\
\hline 생동감이 있다 & & .913 & & & & .882 \\
\hline 활기차다 & & .862 & & & & .862 \\
\hline 신뢰할 만하다 & & & .873 & & & .896 \\
\hline 믿을만 하다 & & & .824 & & & .898 \\
\hline 진실하다 & & & .822 & & & .783 \\
\hline 팔로우하고 싶다 & & & & .846 & & .866 \\
\hline 따라하고 싶은 영향력이 있다 & & & & .839 & & .810 \\
\hline 지인에게 추천하고 싶다 & & & & .740 & & .743 \\
\hline 친밀감이 든다 & & & & & .863 & .878 \\
\hline 친근하다 & & & & & .801 & .852 \\
\hline 편안하다 & & & & & .771 & .815 \\
\hline Eigen Value & 7.325 & 2.439 & 1.353 & 1.081 & .998 & \\
\hline Variance $(\%)$ & 45.782 & 15.246 & 8.456 & 6.759 & 6.235 & \\
\hline cumulated Variance $(\%)$ & 45.782 & 61.028 & 69.484 & 76.244 & 82.479 & \\
\hline
\end{tabular}

Kaiser-Meyer-Olkin $=.860$, Bartlettsphericity test $\chi^{2}=1874.123(\mathrm{df}=120, \mathbf{p}<. \mathbf{0 0 1})$

\section{2 연구문제 2}

인플루언서 속성을 구성하고 있는 요인 중 어떠한 요인이 광고정보성에 영향을 미치는지 확인하고자 다중회귀분석을 실시하였다. 그 결과는 [Table 2]와 같다. 다중회귀분석에서 $\mathrm{F}$ 값을 확인한 결과 $18.551(\mathrm{p}<.001)$ 로 확인되었기에 회귀모형의 적합함을 확인하였다. 또한 종속변수인 광고 정보성에 대한 $\mathrm{R}^{2}$ 은 .395 이며 수정된 $\mathrm{R}^{2}$ 은 .374로 확인되었다. 다중회귀분석에서 잔차의 독립성 여부를 검증하고자 DurbinWatson의 값을 확인하였다. 그 결과 2.117로 나타났다. 일반적으로 Durbin-Watson의 값이 1 3 정도이면 잔차의 독립성에는 큰 문제가 없다고 본다. 또한 독립변수 간의 상관관계가 어떠한지 확인하고자 다중공선성을 판단하기 위해 VIF 값을 확인하였다. 그 결과 2 미만으로 나타났기에 다중공선성이 존재하지 않는 것으로 판단하였다. 이상의 결과를 토대로 인플루언서 속성을 구성하고 있는 요인 중 광고 정보성에 유의미한 영향을 미치는 요인을 확인한 결과 전파성 $(\mathrm{t}=3.973, \mathrm{p}<.001)$ 이 가장 크게 정 $(+)$ 의 영향을 미치는 것으로 나타났다. 다음으로는 역동성 $(\mathrm{t}=3.002, \mathrm{p}<.01)$, 신뢰성 $(\mathrm{t}=2.098, \mathrm{p}<.05)$ 요인 순으로 정 $(+)$ 의 영향이 미치는 것으로 나타났다. 전문성과 친밀성은 광고 정보성에 유의미한 영향이 미치지 않는 것으로 확인되었다.

[표 2] 인플루언서 속성 요인이 광고 정보성에 미치는 영향

[Table 2] Influence of Influencer Attribute Factors on Advertising Information

\begin{tabular}{|c|c|c|c|c|c|c|}
\hline \multirow{2}{*}{ 모형 } & \multicolumn{2}{|c|}{ 비 표준화계수 } & \multirow{2}{*}{ 표준화 계수 } & \multirow{2}{*}{$\mathrm{T}$} & \multicolumn{2}{|c|}{ 공선성 통계량 } \\
\cline { 2 - 4 } \cline { 6 - 7 } & $\mathrm{B}$ & 표준오차 & 베타 & & 공차 & VIF \\
\hline 전문성 & .085 & .077 & .099 & 1.096 & .523 & 1.911 \\
\hline 역동성 & .209 & .069 & .226 & $3.002^{* *}$ & .754 & 1.326 \\
\hline
\end{tabular}




\begin{tabular}{|c|c|c|c|c|c|c|}
\hline 신뢰성 & .190 & .091 & .180 & $2.098^{*}$ & .578 & 1.731 \\
\hline 전파성 & .297 & .075 & .346 & $3.973 * * *$ & .562 & 1.780 \\
\hline 친밀성 & -.011 & .071 & -.013 & -.150 & .567 & 1.763 \\
\hline
\end{tabular}

$* * * \mathrm{p}<.001, * * \mathrm{p}<.01, * \mathrm{p}<.05 \mathrm{~F}=18.551(\mathrm{p}<.001)$ Durbin-Watson=2.117

\section{3 연구문제 3}

인플루언서 속성 요인 중 광고 오락성에 영향을 미치는 요인을 확인하고자 다중 회귀분석을 실시하였다. 분석 결과는 [Table 3]과 같다. 다중회귀분석을 위한 모형 적합도를 확인한 결과 $\mathrm{F}$ 값이 $29.506(\mathrm{p}<.001)$ 으로 확인되어 회귀모형이 적합함을 판단하였다. 종속변수 광고 오락성에 대한 $\mathrm{R}^{2}$ 은 .510 이며 수정된 $\mathrm{R}^{2}$ 은 .492 로 나타났다. 다중회귀분석에서 잔차의 독립성 여부를 검증하고자 Durbin-Watson의 값을 확인하였다. 그 결과 2.158로 나타났다. 따라서 잔차의 독립성이 충족된 것으로 판단하였다. 다중공선성을 판단하기 위해 VIF 값을 확인한 결과 2 미만으로 나타났기에 다중공선성이 존재하지 않는 것으로 확인하였다. 이상의 결과를 토대로 인플루언서 속성을 구성하고 있는 요인 중 광고 오락성에 유의미한 영향을 미치는 요인을 확인한 결과 전파성 $(\mathrm{t}=4.571$, $\mathrm{p}<.001)$ 이 가장 크게 정 $(+)$ 의 영향을 미치는 것으로 나타났다. 다음으로는 신뢰성 $(\mathrm{t}=3.049$, $\mathrm{p}<.01)$, 역동성 $(\mathrm{t}=2.08, \mathrm{p}<.01)$ 요인 순으로 정 $(+)$ 의 영향이 미치는 것으로 나타났다. 전문성과 친밀성은 광고 오락성에 유의미한 영향이 미치지 않는 것으로 확인되었다.

[표 3] 인플루언서 속성 요인이 광고 오락성에 미치는 영향

[Table 3] Influence of Influencer Attribute Factors on Advertising Entertainment

\begin{tabular}{|c|c|c|c|c|c|c|}
\hline \multirow{2}{*}{ 모형 } & \multicolumn{2}{|c|}{ 비 표준화계수 } & \multirow{2}{*}{$\begin{array}{c}\text { 표준화 계수 } \\
\text { 베타 }\end{array}$} & \multirow{2}{*}{$\mathrm{t}$} & \multicolumn{2}{|c|}{ 공선성 통계량 } \\
\hline & B & 표준오차 & & & 공차 & VIF \\
\hline 전문성 & .115 & .080 & .118 & 1.449 & .523 & 1.911 \\
\hline 역동성 & .221 & .072 & .208 & $3.075 * *$ & .754 & 1.326 \\
\hline 신뢰성 & .285 & .093 & .236 & $3.049 * *$ & .578 & 1.731 \\
\hline 전파성 & .353 & .077 & .358 & $4.571 * * *$ & .562 & 1.780 \\
\hline 친밀성 & .028 & .073 & .030 & .379 & .567 & 1.763 \\
\hline
\end{tabular}

$* * * \mathrm{p}<.001, * * \mathrm{p}<.01 \mathrm{~F}=29.506(\mathrm{p}<.001$ Durbin-Watson $=2.158$

\section{4 연구문제 4}

인플루언서 속성 요인 중 광고의 개인화 특성에 영향을 미치는 요인을 확인하고자 다중 회귀분석을 실시하였다. 분석 결과는 [Table 4]와 같다. 다중회귀분석을 위한 모형 적합도를 확인한 결과 $\mathrm{F}$ 값이 $22.049(\mathrm{p}<.001)$ 로 확인되어 회귀모형이 적합한 것으로 확인되었다. 종속변수 광고 오락성에 대한 $\mathrm{R}^{2}$ 은 .437 이며 수정된 $\mathrm{R}^{2}$ 은 .417 로 확인되었다. 다중회귀분석에서 잔차의 독립성 여부를 검증하고자 Durbin-Watson의 값을 확인한 결과 2.158로 나타났다. 따라서 잔차의 독립성이 충족되었음을 확인하였다. 다중공선성을 판단하기 위해 VIF 값을 확인한 결과 2 미만으로 나타났기에 문제가 없음을 확인하였다. 이상의 결과를 토대로 인플루언서 특성을 구성하고 있는 요인 중 광고의 개인화 특성에 영향을 미치는 요인을 확인한 결과 전파성 $(\mathrm{t}=5.474, \mathrm{p}<.001)$ 이 가장 크게 정 $(+)$ 의 영향을 미치는 것으로 나타났다. 다음으로는 역동성 $(\mathrm{t}=2.08, \mathrm{p}<.01)$ 요인 순으로 정 $(+)$ 의 영향이 
미치는 것으로 나타났다. 인플루언서의 특성 요인 중 전문성과 신뢰성 그리고 친밀성은 광고의 개인화 특성에 유의미한 영향이 미치지 않는 것으로 확인되었다.

[표 4] 인플루언서 속성 요인이 광고의 개인화 특성에 미치는 영향

[Table 4] The Effect of Influencer Attribute Factors on the Personalization Characteristics of Advertisements

\begin{tabular}{|c|c|c|c|c|c|c|}
\hline \multirow{2}{*}{ 모형 } & \multicolumn{2}{|c|}{ 비 표준화계수 } & \multicolumn{2}{|c|}{ 표준화 계수 } & \multirow{2}{*}{$\mathrm{t}$} & \multicolumn{2}{|c|}{ 공선성 통계량 } \\
\cline { 2 - 3 } & $\mathrm{B}$ & 표준오차 & 베타 & & 공차 & $\mathrm{VIF}$ \\
\hline 전문성 & .052 & .076 & .059 & .678 & .523 & 1.911 \\
\hline 역동성 & .253 & .068 & .268 & $3.701^{* * * *}$ & .754 & 1.326 \\
\hline 신뢰성 & .128 & .089 & .119 & 1.438 & .578 & 1.731 \\
\hline 전파성 & .403 & .074 & .460 & $5.474^{* * * *}$ & .562 & 1.780 \\
\hline 친밀성 & -.039 & .069 & -.047 & -.559 & .567 & 1.763 \\
\hline
\end{tabular}

*** $\mathrm{p}<.001 \mathrm{~F}=22.049(\mathrm{p}<.001)$ Durbin-Watson=2.163

\section{5. 결론 및 논의}

소셜 인플루언서가 광고 시장의 새로운 주체로 등장하면서 기존의 광고시장에 변화가 일어나고 있다. 또한 콘텐츠의 주요 소비층인 $\mathrm{Z}$ 세대의 행태에 따라 더 짧고 간결한 솟폼 콘텐츠가 주목을 받고 있다. 이러한 맥락에서 기업은 기존의 광고 정보원이 아닌 디지털 마케팅에 적합한 소셜 인플루언서를 활용한 숏폼광고를 적극 활용하고 있다. 디지털 마케팅 변화에 따라 본 연구에서 최근 광고시장에서 화두로 떠오르고 있는 숏폼광고의 소셜 인플루언서 속성을 확인하고 이를 토대로 소비자태도에 미치는 영향을 확인하고자 하였다. 기존의 동영상 광고와는 다른 숏폼광고의 속성을 고려하여 광고 정보성과 광고 오락성 그리고 개인화에 인플루언서의 어떠한 속성들이 영향을 미치는지 그리고 그 영향력은 어떠한지 확인하였다. 실증분석을 통한 연구 결과는 다음과 같다.

먼저, 사전 조사에서 선행연구를 통해 인플루언서의 속성을 확인하였다. 이를 토대로 광고 관련 대학생, 전문가 연구자들을 대상으로 인터뷰를 통해 숏폼광고의 소셜 인플루언서의 속성을 도출하기 위한 17 개 항목을 구축하였다. 이들 항목은 요인분석을 통해 숏폼광고의 인플루언서 속성을 확인한 결과 전문성, 역동성, 신뢰성, 전파성, 친밀성 5 개 요인으로 도출되었다.

둘째, 숏폼광고에서 제공하는 유익한 최신정보 전달에 영향을 미치는 인플루언서 속성은 전파성, 역동성, 신뢰성으로 확인되었다. 소셜 인플루언서를 따라하고 싶거나 이들의 영향력을 공유하며 지인에게 추천하고 싶은 욕구를 느끼게 하는 전파능력이 솟폼 광고 정보성에 가장 큰 영향을 미치는 것으로 확인되었다. 또한 소셜 인플루언서의 생기발랄하고 활동적인 역동성이 광고정보에 영향을 미치며 이들의 진실성이 정보전달에 긍정적인 영향이 미치는 것으로 확인되었다. SNS를 통해 적극적으로 정보를 습득하는 디지털 네이티브에게 숏폼광고를 활용한 기업의 제품정보 전달 방법은 최상의 커뮤니케이션 전략이다. 그림으로 광고정보 전달을 강화하기 위해서는 소셜 인플루언서의 팔로우 능력과 생기발랄한 역동성 그리고 이들의 신뢰성이 중요하게 고려되어야 함을 시사하는 바이다.

셋째, 솟폼광고의 오락성에는 소셜 인플루언서를 따르게 하는 영향력이나 영상이나 게시물은 공유하고 싶은 전파능력이 가장 크게 영향을 미치는 것으로 확인되었다. 
다음으로는 인플루어서의 진실성이나 믿을 만한 신뢰성이 광고 정보성에도 영향을 미치며 이들의 생동감 또한 솟폼광고의 오락성에 영향이 미치는 것을 확인하였다. 숏폼광고는 기존의 광고와는 달리 인플루언서의 활기차고 발랄함을 활용하여 쉽게 따라 할 수 있는 반복적인 비트와 단순 동작으로 솟폼 콘텐츠 이용자들에게 재미와 오락성을 부여하고 있다. 이러한 특성을 활용하여 틱톡에서는 후키송 캠페인을 실행하며 소셜 미디어 이용자들의 2차 가공과 확산에도 큰 영향을 미치고 있다. 인플루언서의 특성과 숏폼 콘텐츠의 특성이 어우러져 소셜 미디어 이용자들에게 숏폼광고를 보는 즐거움과 호기심 제공하며 광고를 보면 기분까지 좋아진다는 시너지 효과를 얻고 있는 것으로 해석된다. 이상의 결과는 기존의 광고가 가지고 있는 광고회피와 불쾌감이라는 문제점을 해소하기 위해 방안으로 솟폼광고의 차별적 특성과 인플루언서의 특성을 고려한 디지털 콘텐츠 마케팅 전략이 지속적으로 개발되어야 함을 사려 드리는 바이다.

넷째, 모바일에 최적화된 영상 기술과 더불어 인플루언서의 팔로우 능력이나 영상물들을 공유하고 지인에게 추천하게 만드는 전파능력이 솟폼광고의 개인화 특성에 영향이 미치는 것을 확인하였다. 또한 인플루언서의 활기차고 생동감 있는 역동성이 숏폼 콘텐츠 이용자들에 적합한 정보를 제공하고 있음을 확인하였다. 디지털 마케팅 특성 중 하나는 데이터 분석을 통해 개개인에게 최적화된 콘텐츠를 제공할 수 있는 환경 구축이다. 이러한 디지털 마케팅의 특성을 활용하여 숏폼광고는 기존 광고와는 달리 이용자 개개인의 욕구 부응과 이들의 관심사에 적합한 제품정보를 인플루언서를 활용하여 제공함으로써 숏폼광고의 거부감보다는 개개인에게 필요한 정보를 제공하는 최적의 콘텐츠로 인식하고 있음을 확인하였다는 것에 함의를 제공하는 바이다.

본 연구의 한계점과 추후 연구를 위한 제언사항은 다음과 같다. 첫째, 본 연구의 응답자 선정이 편의표본추출에 의해 이루어졌다는 한계점을 갖고 있다. 디지털 콘텐츠를 가장 많이 이용하는 세대는 $\mathrm{MZ}$ 세대 이다. 그러나 본 연구에서는 디지털 네이티브 세대들만을 대상으로 연구가 이루어졌다. 디지털 콘텐츠를 소비하는 세대가 늘어나고 있다는 점을 고려할 때 다양한 세대를 고려한 인플루언서의 속성 확인과 숏폼광고에 미치는 영향을 살펴보아야 할 것이다. 둘째, 인플루언서의 유형이나 주로 활동하는 분야에 따라 인플루언서의 속성이 다를 것이지만 이를 고려하지 않은 한계점을 갖고 있다. 추후 연구에서는 인플루언서의 유형이나 주요 활동분야를 고려한 연구가 이루어져야 할 것이다. 셋째, 본 연구의 응답자가 디지털 네이티브이지만 이들의 특성을 고려한 연구가 이루어지지 않았다는 한계점을 갖고 있다. 디지털 네이티브는 개인주의적 성향과 현재 지향적 성향을 갖고 있다. 그러므로 추후 연구에서는 이들의 성향에 따라 변인의 영향력에 차이가 있는지 제언하는 바이다. 이상의 연구가 디지털 마케팅 시대에 숏폼광고를 활용한 인플루언서 전략에 유용한 시사점을 제공할 수 있을 것으로 기대한다.

\section{References}

[1] Changes in content consumption patterns in the mobile era - Creative Band (creative-band.com), Apr 7 (2021)

[2] Ji Won Kim, A Qualitative Study on Generation Z's a Short-Form Fashion Content Consumption and Related Factors: Focused on Media Attitude and Appearance Management Consumption Behavior, The Graduate School Yonsei University, Master's Thesis, (2020)

[3] Short-form contents, https://100.daum.net/encyclopedia/view/201XXX2007095, Apr 25, (2021) 
[4] Seung Hoon Jeong, In the heyday of short-form advertising content, Leferi's' Short Video League' focuses on, Digital Times, http://www.dt.co.kr/contents.html?article_no=2021020902109923805009\&ref=daum, May 1 (2021)

[5] Gyo Soon Park, Short and intense!!! Gen Z who is enthusiastic about short form content, KB Financial Group Management Research Center, (2020), pp.1-10.

[6] Seung Yoon Lee, Jung Gi Ahn, Extraordinary influence of ordinary people Influencer, Nexus Business Sales, (2018)

[7] S. J. Park, C. G. Oh, The Impact of Influencers' Characteristics on YouTube Information Adoption and Purchase Intention, The Journal of Iformation Systems, (2021), Vol.30, No.1, pp.179-204, DOI: https://doi.org/10.5859/KAIS.2021.30.1.179

[8] Eugene Lee, Sae Kyung Yu, The Effect of Short Video Uses on Viewing Behaviors, Korean Journal of Broadcasting and Telecommunication Studies, (2018), Vol.32, No.4, pp.65-102.

[9] Young Seung Lee, The power of a short video! The trending short form content of the video market, Consumer \& media trends, https://kookminadpr.tistory.com/143, May 4 (2021)

[10] Soon Min Hwang, "Income of 4 billion won per year with TikTok" Influencers stand at the fore in short form, Maekyung Premium, https://www.mk.co.kr/premium/special-report/view/2021/04/30033/, Apr 17 (2021)

[11] Mun Hag Lee, Hyun Wook Jung, A Study on the User's Perception of Using TikTok, a Short Video Platform, Journal of Korean Society for the Scientific Study of Subjectivity, (2021), No.54, pp.5-25, DOI: 10.18346/KSSSS.54.1

[12] Jin Lee, A Study on Types of Short-form Video Contents, Humanities Contents, (2020), No.58, pp.121-139.

[13] Ruiyao Ma, Sojung Kim, Use, Motivations, and Responses of TikTok as an Advertising Channel, The Journal of the Korea Contents Association, (2021), Vol.21, No.2, pp. 507-519, DOI: 10.5392/JKCA.2021.21.02.507

[14] Influencer, DAUM encyclopedia, https://100.daum.net/encyclopedia/view/201XXX2012065, Apr 28 (2021)

[15] Hye Young Kim, Joon Hyuk Choi, Development of Endorser Attributes Scale for Social Media Influencer - Focus on YouTube Platform Influencer, Journal of Practical Research in Advertising and Public Relations, (2020), Vol.13, No.4, pp.98-129, DOI: 10.21331/jprapr.2020.13.4.004

[16] A. Audrezet, G. De Kerviler, J. G. Moulard, Authenticity under threat: When social media influencers need to go beyond self-presentation, Journal of Business Research. Advanced online publication, (2020), Vol.117, pp.557-569, DOI: https://doi.org/10.1016/j.jbusres.2018.07.008

[17] M. De Veirman, V. Cauberghe, L. Hudders, Marketing through Instagram influencers: The impact of number of followers and product divergence on brand attitude, International Journal of Advertising, (2017), Vol.36, No.5, pp.798828, DOI: https://doi.org/10.1080/02650487.2017.1348035

[18] 2020 Influencer Content Usage Behavior Survey, DMC Media, Feb 28 (2021)

[19] Shinhyoung Lee, Saetbyeol Kim, The Boomerang Effect of Influencer Marketing: How the Interaction Between Influencer Type and Social Distance Affects Negative Word of Mouth Intentions, Korean Journal of Business Administration, (2019), Vol.32, No.11, pp.2005-2028, DOI: 10.18032/kaaba.2019.32.11.2005

[20] Jong Moo Kim, Research on Model Preference and Consentaneity in TV Commercials - Centering on the Attribute of a Model, Design Convergence Study, (2010), Vol.9, No.3, pp.3-14, UCI: G704-SER000008947.2010.9.3.002

[21] Sungae Park, A Study on Influencers' Effects on the Policy Promotion of Local Governments according to Their Attributes as Sources, Yonsei University, Master's Thesis, (2019)

[22] Jae Hyun Cho, The Influences of Consumer`s Favorable Attitude and Sympathy toward the Celebrity Endorser on Anti-Smoking Campaign, The Korean journal of advertising and public relations, (2008), Vol.10, No.3, pp. 295-317, UCI: G704-001035.2008.10.3.011

[23] Y. J. Kwon, B. S. Hong, S. W. Seo, M. A. Cho, Transactions: The Effects of the Attributes of Korean Celebrity Advertising Models on Chinese Consumer's Intention to Purchase Korean Fashion Brands, Journal of the Korean Society of Clothing and Textiles, (2009), Vol.33, No.3, pp.477-488, DOI: https://doi.org/10.5850/ JKSCT.2009.33.3.477 
[24] S. G. Kim, J. S. Yoon, Factors Affecting the Customer Satisfaction of Mobile Advertising : Focused on the Moderating Effect of Gender and Age, The Journal of Internet Electronic Commerce Research, (2015), Vol.15, No.4, pp.285-302, UCI: G704-001762.2015.15.4.010

[25] H. H. Bauer, T. Reichardt, S. J. Barnes, M. M. Neumann, Driving consumer acceptance of mobile marketing: A theoretical framework and empirical study, Journal of electronic commerce research, (2005), Vol.6, No.3, pp.181-192. 